\title{
BMJ Open Trajectories of sickness absence among salaried workers: evidence from the WORKss cohort in Catalonia (Spain), 2012-2014
}

\author{
Monica Ubalde-Lopez, ${ }^{\oplus 1,2,3}$ Julio C Hernando-Rodriguez, ${ }^{\oplus 1,2,3}$ \\ Fernando G Benavides, ${ }^{1,2,3}$ Laura Serra ${ }^{1,2,3}$
}

To cite: Ubalde-Lopez M, Hernando-Rodriguez JC, Benavides FG, et al. Trajectories of sickness absence among salaried workers: evidence from the WORKss cohort in Catalonia (Spain), 2012-2014. BMJ Open 2019;9:e029092. doi:10.1136/ bmjopen-2019-029092

- Prepublication history and additional material for this paper are available online. To view these files, please visit the journal online (http://dx.doi. org/10.1136/bmjopen-2019029092).

MU-L and JCH-R contributed equally.

Received 14 January 2019 Revised 28 May 2019 Accepted 10 June 2019

Check for updates

(c) Author(s) (or their employer(s)) 2019. Re-use permitted under CC BY-NC. No commercial re-use. See rights and permissions. Published by BMJ.

${ }^{1}$ Department of Experimental and Health Sciences, Centre for Research in Occupational Health (CiSAL), Pompeu Fabra University, Barcelona, Spain ${ }^{2}$ CIBER of Epidemiology and Public Health (CIBERESP),

Barcelona, Spain

${ }^{3}$ IMIM - Parc Salut Mar, Barcelona, Spain

Correspondence to Dr Monica Ubalde-Lopez; monica.ubalde@upf.edu

\section{ABSTRACT}

Objectives Sickness absence (SA) is a widely studied integrated measure of health status. To better understand how SA behaves over time (SA trajectory) a longitudinal and individual-centred approach will allow identifying groups of individuals who share common characteristics. The aim of this study was to identify and describe SA trajectories and to assess employment conditions and diagnosis groups as determinants.

Setting Working-life and sickness absence administrative records from a representative sample of affiliated with the Spanish Social Security system.

Participants 38420 workers affiliated with the Spanish Social Security system, born 1949 to 1969 or 1970 to 1990, resident in Catalonia who had SA between 2012 and 2014 (75212 episodes).

Results We identified three different SA trajectories in both birth cohorts for men and women: low-stable (86.2\% to $90.8 \%$ of individuals), decreasing ( $4.4 \%$ to $5.9 \%$ of individuals) and increasing (4.1\% to $8.7 \%$ of individuals) accumulated days of SA. The main characteristic of SA trajectories was the medical diagnosis group. The increasing SA trajectory had a higher proportion of workers with SA due to mental disorders compared with the other trajectories. The association analysis showed diagnosis group strongly related with all SA trajectories, particularly SA due to mental disorders showed the strongest association with the increasing trajectory among young men (adjusted $\mathrm{OR}(\mathrm{aOR}): 42.40,95 \% \mathrm{Cl} 17.03$ to 105.57). Low salary levels exhibited a strong relationship with decreased accumulation of SA days over time for old women (aOR: $2.08,95 \% \mathrm{Cl} 1.36$ to 3.18 ) and men (aOR: $2.75,95 \% \mathrm{Cl} 1.77$ to 4.27$)$. Unskilled manual occupations were associated with increasing trajectories among young women (aOR: $1.36,95 \% \mathrm{Cl} 1.01$ to 1.84 ). No significant differences were observed for other employment conditions across trajectories.

Conclusions Workers with mental disorders are more likely to have increased days of $S A$, whereas low salary levels at later ages are related to a decrease in SA days over time. Special attention to preventing the course of mental disorders at young and middle age is warranted.
Strengths and limitations of this study

- This study provides novel insight into sickness absence research from a longitudinal and individual-centred approach by investigating sickness absence trajectories.

- Trajectory analysis allows the identification of workers who require specific and early intervention, such as those with mental disorders, which follows an increasing pattern of days of sickness absence over time.

- The use of high-quality administrative registries from a large representative sample of the Spanish working population, together with access to medically certified sickness absence registries, provides higher validity to the results than self-rated sickness absence measures.

- Potential selection bias may be present when classifying workers into categories of accumulated employment-related factors, which could lead to underestimating their relationship with sickness absence trajectories.

- Information related to working conditions, health-related behaviours, healthcare consumption, family structure and prior health status that would be worth considering to identify and describe sickness absence trajectories were not available.

\section{INTRODUCTION}

Sickness absence (SA), considered a holistic measure of health status and work functioning, ${ }^{1}$ is also one of the basic social benefits provided by welfare states to protect workers unable to work temporarily due to a health limitation. ${ }^{1-4} \mathrm{SA}$ has a major impact in terms of social, economical and individual burden. According to the Organisation for Economic Cooperation and Development, the expenditures for SA account for $0.8 \%$ of the European Union's average annual gross domestic product. $^{5}$

Prior research has built a solid body of evidence focused on studying determinants 
and risk factors associated with the incidence and duration of SA episodes. ${ }^{6-9}$ Studies have consistently shown that SA follows different behaviour according to sex and age. ${ }^{10-12}$ As women tend to have a higher incidence of SA and duration generally increases with age, ${ }^{13}$ a separate sex-specific birth cohort analysis would be useful to control for the effect of the study design on assessing the role of other SA determinants. In addition, results from occupational epidemiology, occupational medicine and Social Security schemes in SA research are commonly built on assessing variable-centred measures at one time point or using dichotomous outcomes. ${ }^{14}{ }^{15}$ However, to better understand SA behaviour, a more dynamic longitudinal and person-centred approach is needed, ${ }^{16}$ as it will allow the identification of phenotypes of individuals who share similar patterns of SA over time.

Research on the course of SA over time (ie, SA trajectories) is still scarce. The limited number of studies that have investigated SA trajectories were based on the number of overall spells and/or duration, ${ }^{17-20}$ or due to specific pathologies, such as acute myocardial infarction and depression. ${ }^{21}{ }^{22}$ The aim of this study was to contribute to expanding the evidence to research questions that arise when investigating longitudinal SA behaviour by identifying and describing SA trajectories based on the accumulated days of SA in two sex-specific birth cohorts of Spanish salaried workers and assess the role of employment conditions and diagnosis group as determinants of SA trajectories.

\section{METHODS}

\section{Study population}

The study population ( $\mathrm{n}=38420)$ was based on a sample of workers affiliated with the Spanish Social Security System who were born during the time period 1949 to 1969 or 1970 to 1990, residents of the Catalonia region and had at least one closed episode of SA between 2012 and 2014 (75212 total SA episodes). This sample is part of the Spanish WORKing life Social Security (WORKss) cohort. ${ }^{23}$ Briefly, the WORKss cohort includes an annual sample of $4 \%$ of the total affiliates in the Spanish social security system each year since 2004 (roughly 1.1 million people) who had registered at least one working day. The selection of affiliates followed a panel study methodology using an algorithm of randomised number sequences that match their identification codes. In subsequent years, selected affiliates will continue in the sample if they continue affiliated with the Social Security system. To ensure representativeness, those lost to death or administrative inactivity in a specific year are replaced with an affiliate with similar characteristics from the target until the sample reaches $4 \%$.

SA records were only available for those who live and work in Catalonia, and data were provided by the Catalan Institute for Medical and Health Evaluations. All SA records contain information on the starting/closure date and diagnoses of medically certified SA episodes. In order to ensure a homogeneous working population that shares similar general socioeconomic characteristics and labour market regulations, we selected two birth cohorts: a young cohort of workers born between 1970 and 1990 $(\mathrm{n}=24071,56 \%$ women $)$ and an old cohort born between 1949 and 1969 ( $\mathrm{n}=14349,54 \%$ women), with an age range of 22 to 42 years in the young cohort and 43 to 63 years in the old cohort in 2012.

\section{Patient and public involvement}

Patients were not involved in the study design or conduct of the study. The study was based on secondary administrative records from Spanish social security and the Catalan Institute for Medical and Health Evaluations. The confidentiality of the databases is ensured by a record linkage agreement between Spanish social security, the Catalan Institute for Medical and Health Evaluations and the Centre for Research in Occupational Health-Pompeu Fabra University. Databases arrived to the authors already anonymised.

\section{STATISTICAL ANALYSIS}

Accumulated days of SA were computed quarterly from 2012 to 2014 to estimate SA trajectories using latent class growth analysis (LCGA), which assigns individuals who follow a similar outcome pattern over time to different subgroups. LCGA considers all individuals belonging to a trajectory to be homogeneous and provides an estimation of class membership probabilities for each individual. The optimal number of trajectories was assessed considering both quantitative and qualitative criteria: the Bayesian Information Criterion (BIC), with lower being best, and the likelihood ratio test (LRT) to assess the improvement in fit for the inclusion of one more class, specifically the Lo-Medell-Rubin (LM-LRT). These two criteria give numerical information on goodness of fit. ${ }^{24}$ In addition, to assess class separation, average posterior class probability and entropy were also considered $(>0.80$ indicated good fit). Also, a minimum size of close to $5 \%$ of the study population is preferable for each trajectory group, as SA trajectories with small size could give inaccurate estimates. ${ }^{25}$ In addition, researcher criteria were applied to determine the final number of trajectories. Finally, the associations between employment conditions or diagnosis and SA trajectories were assessed using a multinomial logistic regression model.

The SA trajectories were described by different employment conditions: type of contract (permanent or temporary), working time (full-time, part-time $>50 \%$ up to $99 \%$ and part-time $\leq 50 \%$ ), occupational category (skilled non-manual, skilled manual, unskilled non-manual and unskilled manual) and salary in quartiles. Medical diagnosis was grouped into the main groups according to the $10^{\text {th }}$ revision of the International Classification of Diseases (ICD-10). ${ }^{26}$

As workers can change their category of employment conditions over time, we assigned individuals to the 
category they spent most of the time in paid employment during the follow-up. Similarly, as individuals are likely to have more than one SA episode (43\% of our study population) due to the same or a different medical diagnosis, we assigned them to the diagnosis group that accounted for the greatest number of accumulated days of SA. We tested differences in employment conditions and diagnosis groups among trajectories by applying Pearson's $\mathrm{X}^{2}$ tests for categorical variables and Fisher's test when applicable. The statistical analyses were conducted using Mplus V.7 and R V.3.2.5 for LCGA, and Stata V.13 for the multinomial logistic regression.

\section{RESULTS}

We identified three different trajectories of days accumulated in SA trajectories in both birth cohorts for men and women (figure 1): low-stable $(86.2 \%$ to $90.8 \%$ of individuals), decreasing ( $4.4 \%$ to $5.9 \%$ of individuals) and increasing ( $4.1 \%$ to $8.7 \%$ of individuals) accumulated days of SA. All trajectories had an average probability $>0.8$, the BIC and LM-LRT for model fit reached their optimum values with three classes in the two cohorts, indicating a good model fit, though the entropy hardly reached 0.8 . In men, we identified two trajectory groups of $<5 \%$ of the study population in both birth cohorts, but we decided on three classes because the LM-LRT for model fit confirmed that three classes was better than two classes to describe the observed data $(\mathrm{p}<0.001$ in both cases). In addition, the $\mathrm{BIC}$ was smaller when considering three classes compared with two (111464 vs 112064 in the old cohort, and 167471 vs 168815 in the young cohort; online supplementary appendix 1). The low-stable trajectory was the most represented in both cohorts for both men and women, with a mean of accumulated days of SA per quarter of 7 to 13 days. Decreasing and increasing trajectories exhibited a higher accumulation of SA days, ranging from 63 to 11 and from 7 to 62 days per quarter, respectively, during the 3 years of follow-up (figures 1 and 2).

Regarding employment conditions, we observed significant differences in salary levels among trajectories in both birth cohorts, with the exception of young women. The decreasing trajectories had the highest proportion of workers with low salaries for both men and women (range $14.5 \%$ to $23.1 \%$ ) compared with the other two trajectories. In addition, women in the old birth cohort belonging to the decreasing and low-stable trajectories had the highest proportion of part-time contracts $(27.2 \%$ and $27.6 \%$, respectively) compared with the low-stable trajectory. No significant differences were found by type of contract across trajectories.

The main difference among the three SA trajectories was due to the diagnosis group for both men and women in both birth cohorts. More specifically, the increasing trajectory had a higher proportion of workers with SA due to mental disorders $(19.2 \%$ women and $17.3 \%$ men in the young cohort; $17.4 \%$ women and $9.8 \%$ men in the old cohort) compared with the low-stable and decreasing patterns. Workers with SA due to musculoskeletal disorders were similarly distributed to the decreasing and increasing patterns, with a higher proportion from the old cohort than the young cohort. However, old women significantly accounted for musculoskeletal disorders in the increasing trajectory $(35.2 \%)$, in contrast to the decreasing pattern $(28.9 \%)$. Overall, workers who accumulated SA days for episodes due to infectious and respiratory diseases (tables 1-2) mostly represented the low-stable trajectory. The number of SA episodes followed a similar pattern across trajectories (table 3). Overall, increasing SA trajectories represented to a larger extent long SA spells (median duration range from 25 to 54 days) rather than repeated short ones (data not shown).

The multinomial logistic regression analysis showed that diagnosis was the strongest determinant for all SA trajectories obtained. Compared with episodes due to infectious diseases, individuals who had SA due to mental disorders showed a higher risk to increase accumulated days on SA over time than to develop a low stable trajectory (adjusted OR (aOR): 33.52; 95\% CI 16.40 to 68.51 and aOR: $34.09 ; 95 \%$ CI 10.74 to 108.15 for young and old women, respectively; aOR: 42.40 ; $95 \%$ CI 17.03 to 105.57 for young men). Among old women, SA due to musculoskeletal disorders was associated with an increasing SA trajectory (aOR: 25.35; 95\% CI 8.07 to 79.64), while for young men it showed an association with a decreasing SA trajectory (aOR: 34.83 ; 95\% CI 11.06 to 109.73).

Low salary levels were significantly associated with a higher risk of decreased accumulated days of SA over time compared with the low stable SA trajectory among older women (aOR: 2.08; 95\% CI 1.36 to 3.18 ) and men (aOR: $2.75 ; 95 \%$ CI 1.77 to 4.27 ). A similar but weaker association was found among low salary levels and a higher risk of increasing SA trajectories (aOR: 1.51; 95\% CI 1.01 to 2.26 for women and aOR: 1.56 ; $95 \%$ CI 1.11 to 2.19 for men). Unskilled manual occupations were associated with an increasing SA trajectory for young women (aOR: $1.36 ; 95 \%$ CI1.01 to 1.84 ) (table 4 ).

\section{DISCUSSION}

In this study, three SA trajectories were identified in two birth cohorts of salaried Spanish workers residing in Catalonia during 3 years of follow-up: low-stable, decreasing and increasing accumulated days of SA. We found that the medically certified diagnosis that caused the SA episode was the main factor characterising SA trajectory. More specifically, the increasing trajectory was characterised by a higher proportion of young women who accumulated more days and spells of SA due to mental disorders. Regarding employment conditions, we found that decreasing trajectories had the highest proportion of individuals with low salary levels; the decreasing and low-stable trajectories had the highest proportion of older women with part-time employment. In the association analysis, we found diagnosis to be the strongest determinant for all SA trajectories, particularly SA due to mental disorders with increasing SA trajectories among 

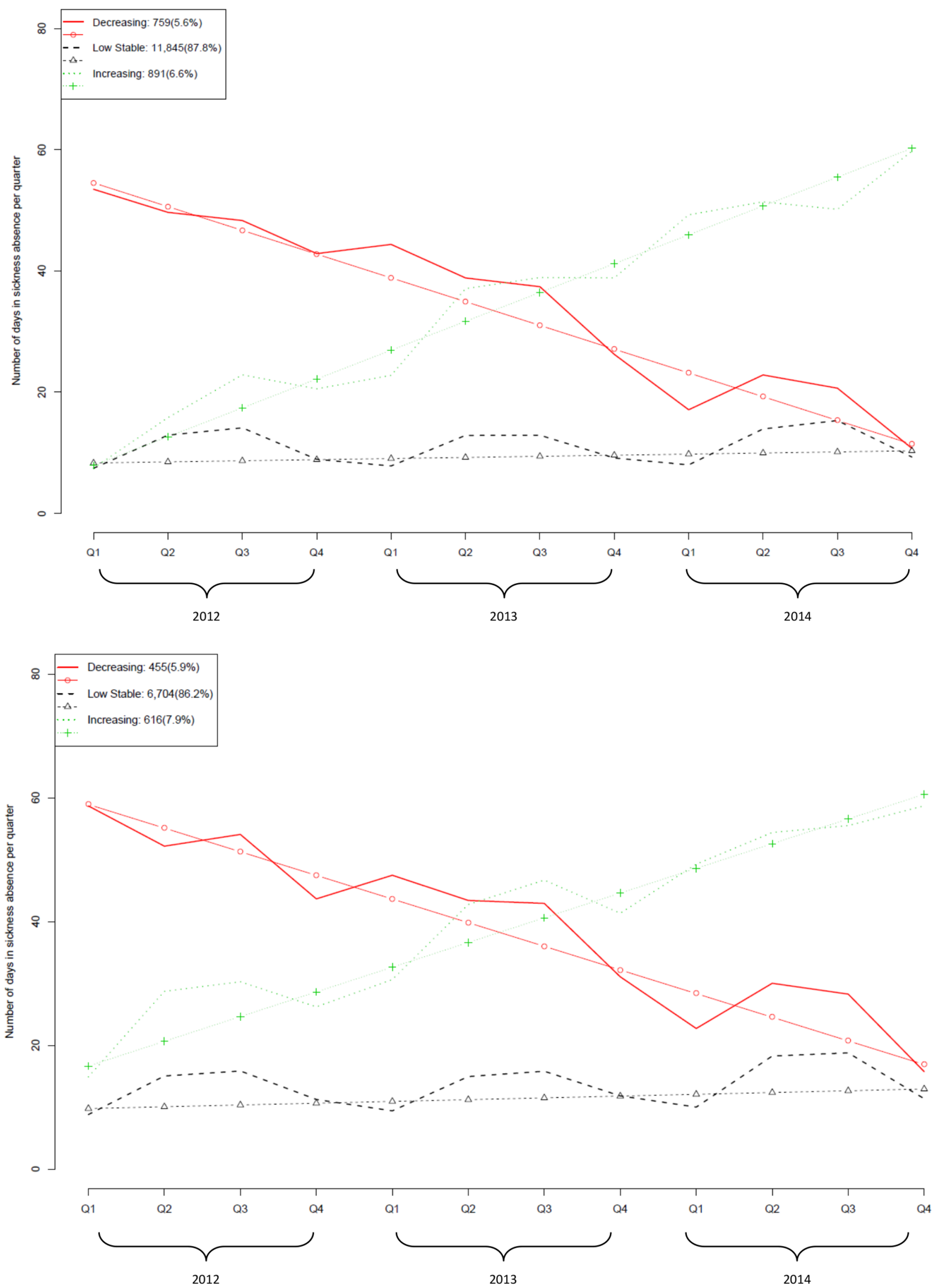

Figure 1 Trajectories of accumulated days of sickness absence per quarter in women born between 1970 to $1990(n=13495)$ or 1949 to 1969 ( $n=7775)$. Catalonia, 2012-2014. 

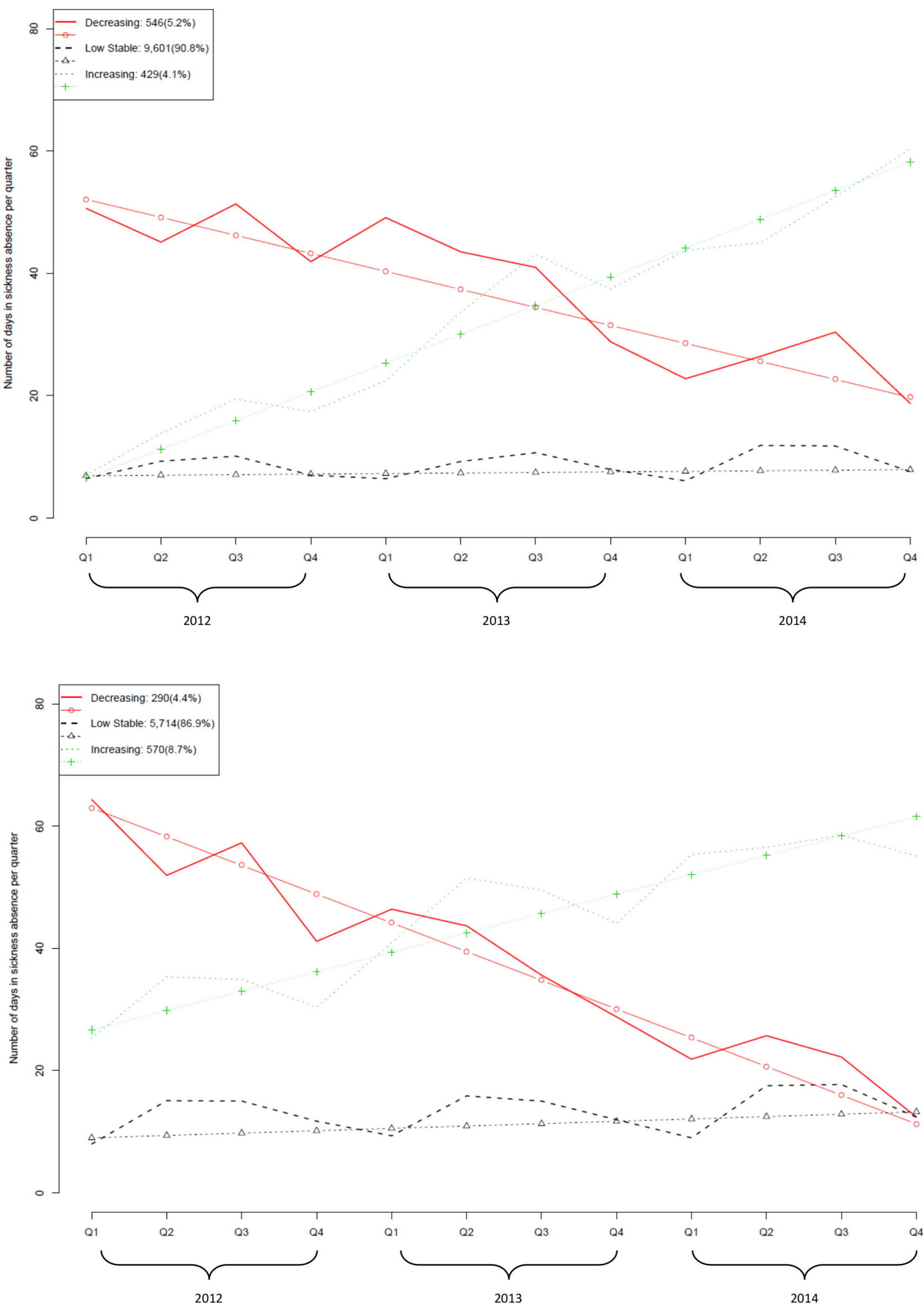

Figure 2 Trajectories of accumulated days of sickness absence per quarter in men born between 1970 to $1990(n=10576)$ or 1949 to 1969 (n=6574). Catalonia, 2012-2014. 
Table 1 Description of sickness absence trajectories in salaried women from the WORKss cohort $(n=21270)$ based on employment conditions and diagnosis group. Catalonia, 2012-2014

\begin{tabular}{|c|c|c|c|c|c|c|c|c|}
\hline \multirow[b]{3}{*}{ Women } & \multicolumn{4}{|c|}{ Cohort born 1970-1990 (n=13495) } & \multicolumn{4}{|c|}{ Cohort born 1949-1969 (n=7775) } \\
\hline & \multirow{2}{*}{$\begin{array}{l}\begin{array}{l}\text { Decreasing } \\
(5.6 \%)\end{array} \\
\mathrm{N}(\%)\end{array}$} & \multirow{2}{*}{$\begin{array}{l}\begin{array}{l}\text { Low-stable } \\
(87.8 \%)\end{array} \\
\mathrm{N}(\%)\end{array}$} & \multirow{2}{*}{$\begin{array}{l}\text { Increasing } \\
(6.6 \%) \\
N(\%) \\
\end{array}$} & \multirow{2}{*}{ P value* } & \multirow{2}{*}{$\begin{array}{l}\begin{array}{l}\text { Decreasing } \\
(5.9 \%)\end{array} \\
\mathrm{N}(\%)\end{array}$} & \multirow{2}{*}{$\begin{array}{l}\begin{array}{l}\text { Low-stable } \\
(86.2 \%)\end{array} \\
\mathrm{N}(\%)\end{array}$} & \multirow{2}{*}{$\begin{array}{l}\begin{array}{l}\text { Increasing } \\
(7.9 \%)\end{array} \\
\mathrm{N}(\%) \\
\end{array}$} & \multirow[b]{2}{*}{ P value } \\
\hline & & & & & & & & \\
\hline \multicolumn{9}{|l|}{ Type of contract } \\
\hline $\begin{array}{l}\text { Permanent } \\
\text { contract }\end{array}$ & $572(75.4)$ & $8737(73.8)$ & $687(77.1)$ & 0.063 & $386(84.8)$ & $5639(84.1)$ & $523(84.9)$ & 0.818 \\
\hline Temporary contract & $187(24.6)$ & $3108(26.2)$ & 204 (22.9) & & 69 (15.2) & $1065(15.9)$ & $93(15.1)$ & \\
\hline \multicolumn{9}{|l|}{ Working time } \\
\hline Full-time & $474(62.5)$ & $7717(65.1)$ & $559(62.7)$ & 0.313 & $331(72.8)$ & $4854(72.4)$ & $473(76.8)$ & 0.009 \\
\hline $\begin{array}{l}\text { Part-time: }>50 \% \text { up } \\
\text { to } 99 \%\end{array}$ & $196(25.8)$ & $2814(23.8)$ & $233(26.2)$ & & 57 (12.5) & 1056 (15.8) & $71(11.5)$ & \\
\hline$\leq 50 \%$ & $89(11.7)$ & $1314(11.1)$ & $99(11.1)$ & & $67(14.7)$ & $794(11.8)$ & $72(11.7)$ & \\
\hline \multicolumn{9}{|c|}{ Occupational category } \\
\hline Skilled non-manual & $146(19.5)$ & $2554(21.9)$ & $193(22.2)$ & 0.379 & $78(17.6)$ & $1387(21.2)$ & $105(17.8)$ & 0.047 \\
\hline Skilled manual & $121(16.2)$ & $1739(14.9)$ & $136(15.6)$ & & $68(15.3)$ & $1056(16.1)$ & $91(15.5)$ & \\
\hline $\begin{array}{l}\text { Unskilled non- } \\
\text { manual }\end{array}$ & $411(55.0)$ & $6309(54.0)$ & $446(51.3)$ & & $211(47.5)$ & $3022(46.1)$ & $270(45.9)$ & \\
\hline Unskilled manual & $69(9.2)$ & $1089(9.3)$ & 95 (10.9) & & 87 (19.6) & $1087(16.6)$ & $122(20.8)$ & \\
\hline \multicolumn{9}{|l|}{ Salary in quartiles } \\
\hline High & $240(31.7)$ & 3858 (32.6) & $299(33.5)$ & 0.619 & $120(26.4)$ & $2061(30.8)$ & $150(24.4)$ & \\
\hline Middle-high & $240(31.7)$ & $3743(31.6)$ & $300(33.7)$ & & $121(26.6)$ & $2156(32.2)$ & 207 (33.6) & \\
\hline Middle-low & $194(25.6)$ & $2973(25.1)$ & $211(23.7)$ & & $130(28.6)$ & $1632(24.4)$ & $165(26.8)$ & $<0.001$ \\
\hline Low & $83(11.0)$ & $1266(10.7)$ & $81(9.1)$ & & $84(18.5)$ & $850(12.7)$ & $94(15.3)$ & \\
\hline \multicolumn{9}{|c|}{ Diagnosis group (ICD-10) } \\
\hline Infectious & $9(1.2)$ & $1240(10.5)$ & $8(0.8)$ & $<0.001$ & $3(0.6)$ & $502(7.5)$ & $3(0.4)$ & $<0.001$ \\
\hline Neoplasms & $17(2.2)$ & $187(1.6)$ & $22(2.5)$ & & $37(8.2)$ & $221(3.3)$ & $28(4.6)$ & \\
\hline Mental & $117(15.4)$ & $792(6.7)$ & $171(19.2)$ & & $69(15.2)$ & $511(7.6)$ & $107(17.4)$ & \\
\hline Cardiovascular & $11(1.5)$ & $178(1.5)$ & $16(1.8)$ & & $23(5.1)$ & $170(2.5)$ & $17(2.8)$ & \\
\hline Respiratory & $6(0.8)$ & $2560(21.7)$ & $18(2.0)$ & & $20(4.4)$ & $1483(22.2)$ & $15(2.4)$ & \\
\hline Digestive & $23(3.0)$ & $554(4.7)$ & $26(2.9)$ & & $20(4.4)$ & $340(5.1)$ & $23(3.7)$ & \\
\hline Musculoskeletal & $253(33.4)$ & $2464(20.8)$ & $300(33.7)$ & & $131(28.9)$ & $1374(20.5)$ & 217 (35.2) & \\
\hline Pregnancy & $107(14.1)$ & $700(5.9)$ & $135(15.2)$ & & $5(1.1)$ & $25(0.4)$ & $3(0.5)$ & \\
\hline $\begin{array}{l}\text { Injuries and } \\
\text { poisoning }\end{array}$ & $69(9.1)$ & $734(6.2)$ & $63(7.1)$ & & $61(13.4)$ & $564(8.4)$ & $85(13.8)$ & \\
\hline Other & 146 (19.3) & 2417 (20.4) & $132(14.8)$ & & 85 (18.7) & 1506 (22.5) & 118 (19.2) & \\
\hline Total & 759 (100.0) & $11845(100.0)$ & $891(100.0)$ & & 455 (100.0) & $6704(100.0)$ & $616(100.0)$ & \\
\hline
\end{tabular}

*Missing values in occupational category (OC), income (I) and diagnosis group (DG): N(\%) in the cohorts born 1970 to 1990 (decreasing DG, 3 (0.55); low-stable - OC, 4 (0.04); I, 1 (0.01); DG, 25 (0.26); increasing - OC, 1 (0.23)) and 1949 to 1969 (low-stable - OC, 4 (0.07); DG, 9 (0.16); increasing - OC, $3(0.52)$ ) by sickness absence trajectory in the period 2012 to 2014 . Salary quartiles based on the average individual salary in the cohorts born 1970 to 1990 (high: 63 778€, middle-high: $21656 €$, middle-low: $13630 €$, low: $6274 €$ ) and 1949 to 1969 (high: $81226 €$, middle-high: 25 283€, middle-low: 15 701€, low: 8307€) in the period 2012 to 2014.

${ }^{*} \chi^{2}$ tests. ICD-10, International Classification of Diseases, 10 th revision.

young men. This result is expected, as the SA trajectory is based on accumulated days of SA, which is closely linked to the prognosis of specific diseases. ${ }^{27}$ Low salary levels had a higher risk of decreased accumulated days of SA over time and a weaker association for increasing SA trajectories for older women and men, as well as unskilled occupations increasing SA days over time among young women.

Most workers shared a low-stable pattern driven by accumulated SA days due to infectious or respiratory diseases or musculoskeletal disorders, with a mean $<20$ 
Table 2 Description of sickness absence trajectories in salaried men from the WORKss cohort $(n=17150)$ based on employment conditions and diagnosis group. Catalonia, 2012-2014

\begin{tabular}{|c|c|c|c|c|c|c|c|c|}
\hline \multirow[b]{3}{*}{ Men } & \multicolumn{4}{|c|}{ Cohort born 1970-1990 ( $n=10576)$} & \multicolumn{4}{|c|}{ Cohort born 1949-1969 $(n=6574)$} \\
\hline & \multirow{2}{*}{$\begin{array}{l}\text { Decreasing } \\
(5.2 \%) \\
\mathrm{N}(\%) \\
\end{array}$} & \multirow{2}{*}{$\begin{array}{l}\text { Low-stable } \\
(90.8 \%) \\
\text { N (\%) }\end{array}$} & \multirow{2}{*}{$\begin{array}{l}\text { Increasing } \\
(4.1 \%) \\
\mathrm{N}(\%) \\
\end{array}$} & \multirow{2}{*}{ P value ${ }^{*}$} & \multirow{2}{*}{$\begin{array}{l}\text { Decreasing } \\
(4.4 \%) \\
N(\%) \\
\end{array}$} & \multirow{2}{*}{$\begin{array}{l}\begin{array}{l}\text { Low-stable } \\
(86.9 \%)\end{array} \\
\mathrm{N}(\%)\end{array}$} & \multirow{2}{*}{$\begin{array}{l}\text { Increasing } \\
(8.7 \%) \\
\mathrm{N}(\%)\end{array}$} & \multirow[b]{2}{*}{ P value } \\
\hline & & & & & & & & \\
\hline \multicolumn{9}{|l|}{ Type of contract } \\
\hline $\begin{array}{l}\text { Permanent } \\
\text { contract }\end{array}$ & 416 (76.2) & 7306 (76.1) & $346(80.6)$ & 0.095 & $241(83.1)$ & $4862(85.1)$ & 476 (83.5) & 0.419 \\
\hline $\begin{array}{l}\text { Temporary } \\
\text { contract }\end{array}$ & $130(23.8)$ & 2295 (23.9) & $83(19.4)$ & & 49 (16.9) & $852(14.9)$ & $94(16.5)$ & \\
\hline \multicolumn{9}{|l|}{ Working time } \\
\hline Full-time & $473(86.6)$ & 8377 (87.2) & $365(85.0)$ & 0.087 & $256(88.2)$ & $5187(90.8)$ & $506(88.8)$ & 0.079 \\
\hline $\begin{array}{l}\text { Part- } \\
\text { time: }>50 \% \text { up to } \\
99 \%\end{array}$ & $32(5.9)$ & $648(6.8)$ & $26(6.1)$ & & $10(3.5)$ & $184(3.2)$ & $15(2.6)$ & \\
\hline$\leq 50 \%$ & $41(7.5)$ & $576(6.0)$ & $38(8.9)$ & & $24(8.3)$ & $343(6.0)$ & $49(8.6)$ & \\
\hline \multicolumn{9}{|c|}{ Occupational category } \\
\hline $\begin{array}{l}\text { Skilled non- } \\
\text { manual }\end{array}$ & $57(10.4)$ & 1269 (13.2) & $44(10.2)$ & 0.094 & 62 (21.3) & $1144(20.0)$ & $100(17.6)$ & 0.756 \\
\hline Skilled manual & $239(43.8)$ & $3916(40.8)$ & $172(40.2)$ & & $113(39.0)$ & $2323(40.7)$ & 243 (42.9) & \\
\hline $\begin{array}{l}\text { Unskilled non- } \\
\text { manual }\end{array}$ & $160(29.3)$ & 3009 (31.4) & $151(35.3)$ & & $87(30.0)$ & $1677(29.4)$ & $162(28.6)$ & \\
\hline Unskilled manual & $90(16.5)$ & 1403 (14.6) & $61(14.3)$ & & $28(9.7)$ & $566(9.9)$ & $62(10.9)$ & \\
\hline \multicolumn{9}{|l|}{ Salary in quartiles } \\
\hline High & $173(31.7)$ & $3083(32.1)$ & $143(33.4)$ & 0.004 & $66(22.8)$ & $1565(27.4)$ & $132(23.1)$ & $<0.001$ \\
\hline Middle-high & $152(27.8)$ & 3171 (33.0) & 137 (31.9) & & $81(27.9)$ & 1789 (31.3) & 177 (31.1) & \\
\hline Middle-low & $142(26.0)$ & 2455 (25.6) & $109(25.4)$ & & $76(26.2)$ & $1604(28.1)$ & 154 (27.0) & \\
\hline Low & $79(14.5)$ & 891 (9.3) & $40(9.3)$ & & $67(23.1)$ & $756(13.2)$ & $107(18.8)$ & \\
\hline \multicolumn{9}{|c|}{ Diagnosis group (ICD-10) } \\
\hline Infectious & $3(0.5)$ & $1309(13.7)$ & $5(1.1)$ & $<0.001$ & $5(1.6)$ & $413(7.2)$ & $4(0.7)$ & $<0.001$ \\
\hline Neoplasms & $7(1.3)$ & $60(0.6)$ & $9(2.0)$ & & $19(6.6)$ & $120(2.1)$ & $23(4.0)$ & \\
\hline Mental & $80(14.7)$ & $456(4.8)$ & $74(17.3)$ & & $24(8.3)$ & $279(4.9)$ & $56(9.8)$ & \\
\hline Cardiovascular & $16(3.0)$ & $187(2.0)$ & $9(2.1)$ & & $27(9.3)$ & $234(4.1)$ & $42(7.4)$ & \\
\hline Respiratory & $19(3.5)$ & $2503(26.1)$ & $14(3.3)$ & & $11(3.8)$ & $1181(20.7)$ & $26(4.6)$ & \\
\hline Digestive & $32(5.9)$ & $626(6.5)$ & $43(10.0)$ & & $22(7.6)$ & $531(9.3)$ & $61(10.7)$ & \\
\hline Musculoskeletal & $126(23.2)$ & $1562(16.3)$ & $92(21.5)$ & & $89(30.7)$ & $1216(21.3)$ & $171(30.0)$ & \\
\hline $\begin{array}{l}\text { Injuries and } \\
\text { poisoning }\end{array}$ & $186(34.3)$ & $1291(13.5)$ & $129(30.1)$ & & $36(12.4)$ & $482(8.5)$ & 69 (12.1) & \\
\hline Other & $74(13.6)$ & $1582(16.5)$ & $54(12.6)$ & & $57(19.7)$ & $1249(21.9)$ & $118(20.7)$ & \\
\hline Total & $546(100.0)$ & $9601(100.0)$ & $429(100.0)$ & & $290(100.0)$ & $5714(100.0)$ & $570(100.0)$ & \\
\hline
\end{tabular}

Missing values in occupational category (OC), income (I) and diagnosis group (DG): N(\%) in the cohorts born 1970 to 1990 (decreasing - DG, 3(0.55); low-stable - OC, 4 (0.04); I, 1 (0.01); DG, 25 (0.26); increasing - OC, 1 (0.23)) and 1949 to 1969 (low-stable - OC, $4(0.07)$; DG, 9 (0.16); increasing - OC, $3(0.52)$ ) by sickness absence trajectory in the period 2012 to 2014 . Salary quartiles based on the average individual salary in the cohorts born 1970 to 1990 (high: 78 928€, middle-high: 25 944€, middle-low: $16710 €$, low: $7209 €$ ) and 1949 to 1969 (high: $99880 €$, middle-high: 36 095€, middle-low: 23 227€, low: $14171 €$ ) in the period 2012 to 2014.

${ }^{*} \chi^{2}$ tests. ICD-10, International Classification of Diseases, 10 th revision.

accumulated days of SA each quarter. These diagnosis groups included pathologies that usually represent acute disease processes that lead to short-term SA episodes. ${ }^{28}$ We identified, especially among young workers, a small but not negligible group with increased accumulated days of SA due mainly to mental disorders, followed by musculoskeletal disorders. SAs due to mental health problems have continuously increased in recent years and shown 


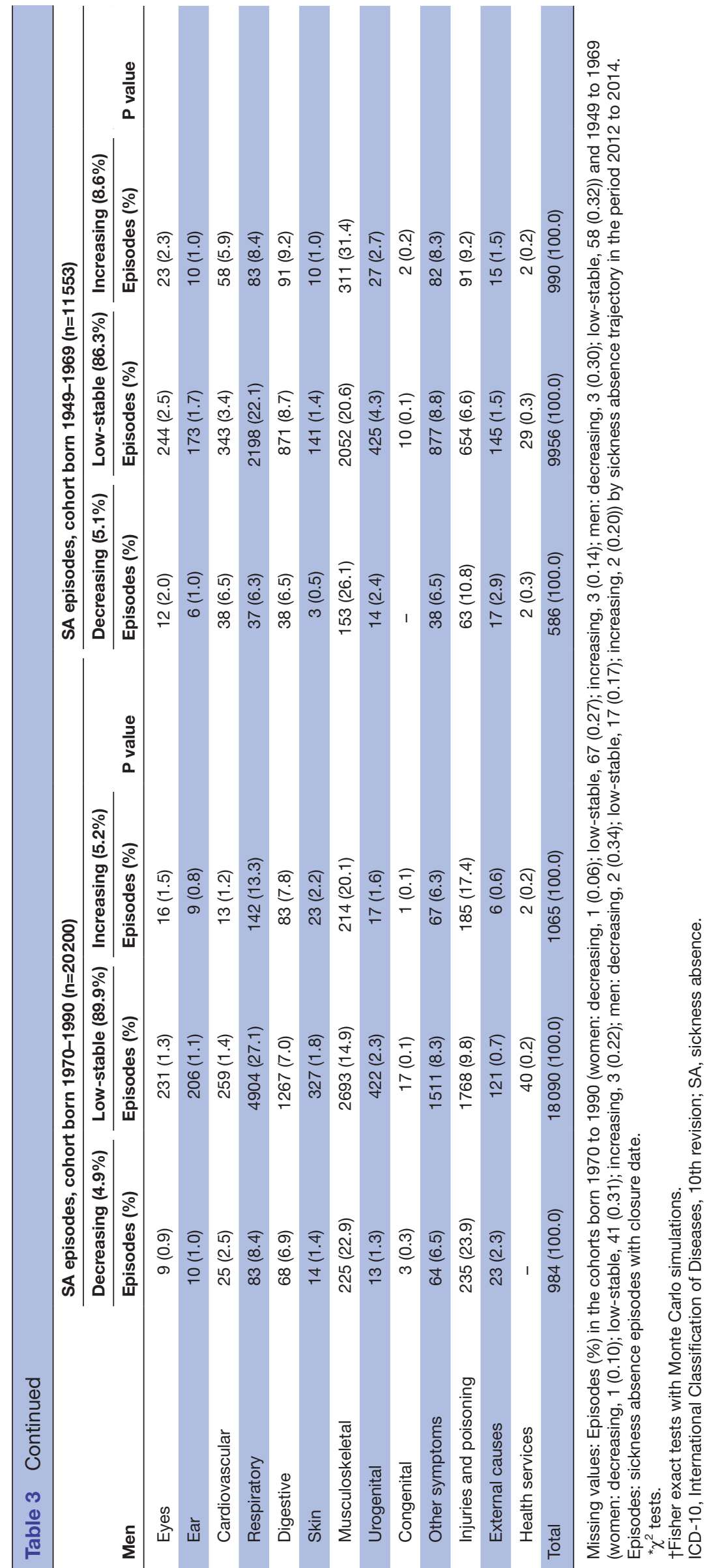




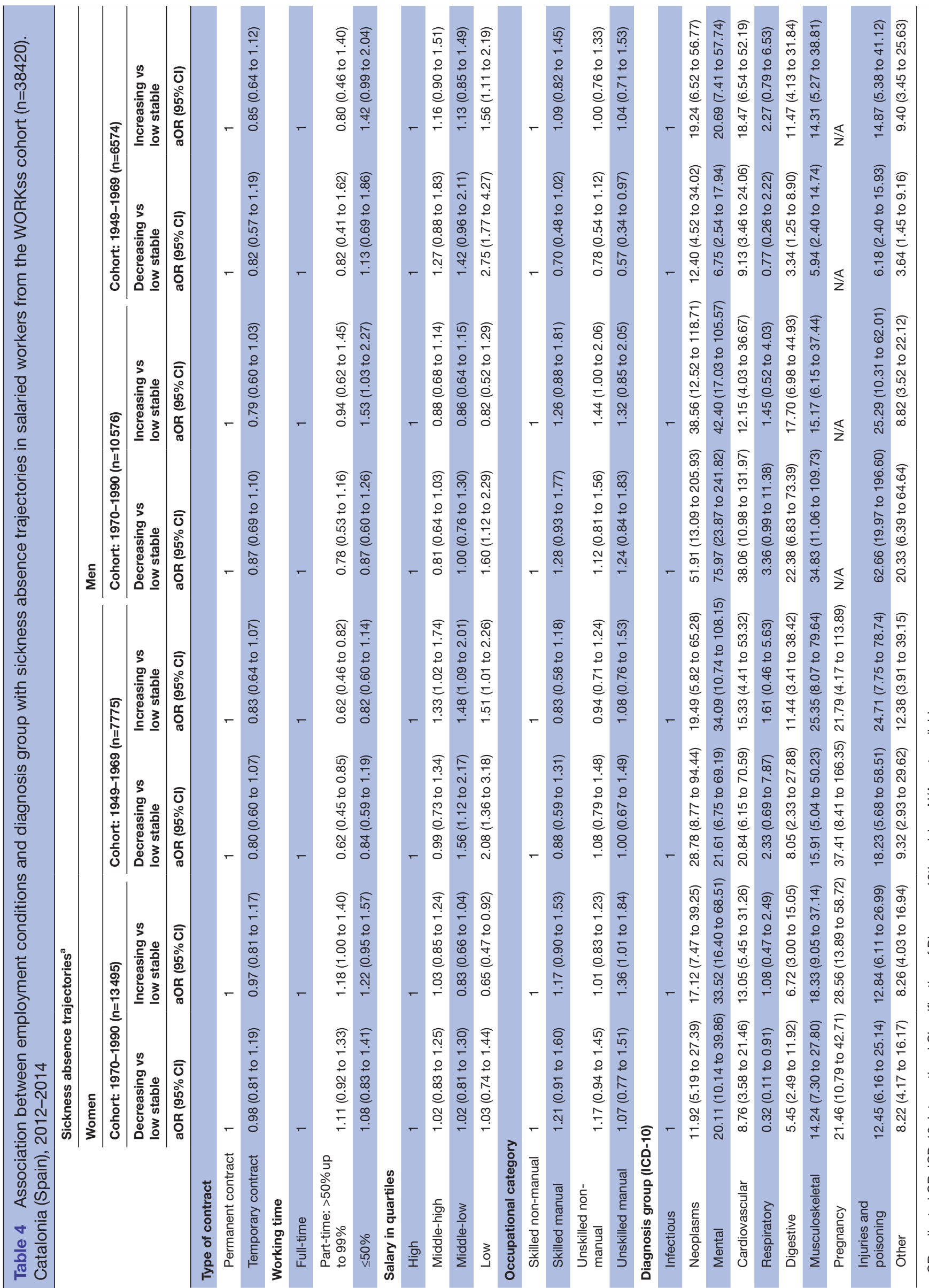

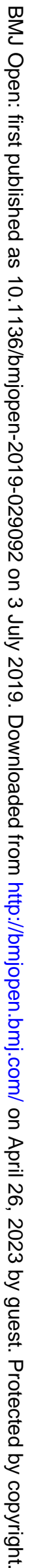


in a UK study to be the main medical diagnosis of longterm SA, above musculoskeletal disorders. ${ }^{12}$ Common mental disorders, such as anxiety and depression, are strong predictors of long-term and recurrent SA, and they affect health over an extended period. ${ }^{29}$ A Finnish study investigating SA trajectories preceding disability retirement showed that patients belonging to the highstable SA trajectory were more likely to retire because of common mental disorders. ${ }^{27}$ Recently, sociodemographic factors, morbidity characteristics and employment status were found to be predictors of work disability trajectory among workers struggling with long-lasting SA depressive episodes. ${ }^{22}$ In our study, the increasing trajectory revealed a concerning group of workers who had a continuously increasing number of days out of work due to mental health-related diagnoses. Facing an unbalanced relationship between mental health limitations and work-related demands may be a cause of a delayed return to work, with recurrent SA episodes and steadily accumulating SA days over time. We found this pattern to be more noticeable among all women and young men. A further step should be to investigate the in depth patterns of SA due to mental diagnoses and its predictors among the young-middle age working population. Our study took a broad approach to examining the general picture of SA patterns over time among a Spanish working population; a diagnosis-specific approach would help disentangle SA trajectories more accurately. However, as we included the total number of SA episodes, our study accounts for SA recurrence, but only for the 3 years of follow-up.

Mental disorders and musculoskeletal disorders are the leading causes of long-term SA. ${ }^{30}$ In general, approximately one in four SA episodes are due to musculoskeletal disorders. ${ }^{31}$ Similarly, we found musculoskeletal disorders distributed across the two non-stable trajectories. In a prior study, high-stable work absence patterns were strongly associated with the number of pain sites in middle-aged workers. ${ }^{18}$ Workers belonging to this trajectory likely had more severe, long-lasting musculoskeletal pathologies and accumulated multiple pain locations. In contrast, those in the decreasing and low-stable patterns may have had SA episodes due to other isolated, acute and short-term specific musculoskeletal diagnoses, such as cervical or low back pain. As physical and mental ill-health are associated, musculoskeletal disorders may also be considered as a somatisation of a mental health problems or co-occur with a diagnosed mental pathology, ${ }^{32}{ }^{33}$ leading to a limited health status that accumulates long periods of SA. ${ }^{34}$

We found that, apart from salary, employment conditions did not define the SA patterns. However, a higher proportion of workers with low salary had a decreased number of days of SA over time compared with the other two SA patterns. Disincentives related to SA benefits payment regulation could partially explain this result. In Spain, entitlement to SA benefits starts the fourth sick day, with a maximum duration of 1 year, and an extension of 6 months if recovery is expected during this period.
The amount of SA benefit varies between $60 \%$ and $75 \%$ of the salary for private sector employees; the employer pays from the 4 th to 15 th day and the Social Security system from the 16 th day onwards. ${ }^{35}{ }^{36}$ It is likely that loss of economical resources, particularly among workers with the lowest salaries, encourage them to return to work earlier, reducing the number of days of SA and receiving a reduced income from benefits. Second, perceived insecurity associated with more precarious employment conditions could lead to a fear of dismissal. ${ }^{37}$ Changes in labour market regulations in 2012 in Spain led to more flexible labour relationships, which has contributed to an increase in unstable workplaces and perceived insecurity. ${ }^{38}$ The association analysis showed that low salary was a determinant of both decreasing and increasing SA trajectory among older workers. A possible explanation for a decreasing number of days of SA, as mentioned above, may be presenteeism (ie, to attend to work while sick) due to reduced economical coverage of the SA provision. Along these lines, a US study found that more than half of workers went to work sick due to a lack in coverage of paid SA. ${ }^{39}$ In addition, presenteeism could affect older workers more because of higher perceived job insecurity, as they know that in the case of job loss their chances of getting a new job are reduced compared with their younger counterparts. On the other hand, increased SA days related to low salary may be explained because workers postpone the onset of the SA episode as much as possible to maintain their full salary, while the existing health problem becomes more severe and the SA becomes longer. Similarly, a comorbidity could arise during an SA, which could lead to a long-term SA, especially in the case of mental or musculoskeletal disorders with one or more co-diagnoses. ${ }^{34}$ In addition, it is possible that, to a lesser extent, the replacement rate for long-term SA episodes (representing $75 \%$ of the salary from day 21 onwards in Spain) may be an incentive to lengthen the SA. Some studies have shown that increases in the generosity of the SA provision are related to increases in SA duration, and that this increase does not translate into an improvement in employee health. ${ }^{41}$ However, another study showed that generous SA benefits are related to a decrease in the number of days of SA in the long-term, which supports that no incentive exists to extend SA longer than strictly necessary for medical reasons. ${ }^{4}$

A large body of prior research has found worst health outcomes for temporary workers, ${ }^{42-44}$ but our study showed that employment conditions, such as type of contract, working time and occupational category, did not differ across SA patterns. One limitation to consider is a potential selection bias when classifying workers into categories of employment conditions. We classified individuals based on the employment condition in which they spent the most time. However, a person who was mainly employed with a permanent contract during the follow-up could, for example, accumulate more days on SA while employed as a temporary worker. This may lead to an underestimation of the relationship between 
employment conditions and SA patterns. Similarly, information related to working-related conditions, health-related behaviours, healthcare consumption and family structure that would be worth considering to identify and describe SA patterns were not available. In addition, accounting for the effect of baseline health status prior to the SA follow-up was not possible because of the lack of health-related data and prior SA episodes. Finally, SA episodes without a closure date were not included in the study; thus, we were not accounting for some ongoing long-term episodes and may have underestimated accumulated days of SA.

Our findings are likely to be relevant to other working populations. The data came from a high-quality administrative registry that provides a large representative sample of the working population appropriated for the aim of our study. Health-related data derived from medical diagnosis certifications conducted by general physicians from the National Health Service provides a higher validity of results compared with self-reported SA measures, as shown in other studies. ${ }^{45}$ In addition, selection of the two birth cohorts allowed us to control for the potential effects of age and contextual factors on SA behaviour, as each cohort includes individuals that share similar socioeconomic characteristics and labour market regulation contexts.

Our results from the trajectory analysis may be useful for guiding occupational health professionals in the more accurate identification of individuals who need support to maintain their work ability and facilitate their return to work. As mental disorders seem to drive a pattern of increasing SA, early detection of workers at risk of mental disorders would help in developing more tailored interventions to deal with and prevent mental health problems in future working life, especially among young workers. Future research should focus on patterns of SA by diagnosis groups and specific pathologies over time. Special attention is warranted on the course of mental disorders among young and middle-aged workers.

Acknowledgements We thank the Spanish National Social Security Institute and the Catalonian Institute for Medical Evaluations for transferring data from the Continuous Working Life Sample and sickness absence registers, respectively.

Contributors All listed authors fulfil authorship criteria. MU-L, LS and FGB participated in the conception and design of the study. JCH-R and LS performed the data management and data analysis. MU-L, FGB, JCH-R and LS interpreted the data. JCH-R and MU-L drafted the first version of the manuscript. MU-L, FGB and LS made subsequent revisions, and all of the authors revised the final version, agreed with the text and findings and approved this final version. MU-L and JCH-R have equally contributed to this work. The corresponding author certifies that all listed authors meet authorship criteria. MU-L is the guarantor.

Funding The study was financed by the State Plan for Investigation, Development and Innovation, 2013- 2016, by the Health Institute Carlos III - Subdirection General of Evaluation and Promotion of Investigation (Grants FIS PI17/00220 and PI14/00057), by the European Regional Development Fund-FEDER, and the CIBER in Epidemiology and Public Health-CIBERESP.

Competing interests None declared.

Patient consent for publication Not required.

Ethics approval This study was approved by Parc de Salut Mar Ethics Committee in Barcelona under research project number 2017/7398/l.
Provenance and peer review Not commissioned; externally peer reviewed.

Data sharing statement Data may be obtained from a third party and are not publicly available.

Open access This is an open access article distributed in accordance with the Creative Commons Attribution Non Commercial (CC BY-NC 4.0) license, which permits others to distribute, remix, adapt, build upon this work non-commercially, and license their derivative works on different terms, provided the original work is properly cited, appropriate credit is given, any changes made indicated, and the use is non-commercial. See: http://creativecommons.org/licenses/by-nc/4.0/.

\section{REFERENCES}

1. Marmot M, Feeney A, Shipley M, et al. Sickness absence as a measure of health status and functioning: from the UK Whitehall II study. J Epidemiol Community Health 1995;49:124-30.

2. International Labour Organization. The Future of Work We Want: A global dialogue. $2017 \mathrm{http}: / /$ socialprotection-humanrights.org/wpcontent/uploads/2017/10/The-Future-of-Work-We-Want_2017.pdf (Accessed 8 Jul 2018).

3. Ministerio de Empleo y Seguridad Social. Incapacidad temporal. 2015 http://www.seg-social.es/prdi00/groups/public/documents/ binario/47197.pdf (Accessed 21 Feb 2017).

4. Sjöberg O. Positive welfare state dynamics? Sickness benefits and sickness absence in Europe 1997-2011. Soc Sci Med 2017;177:158-68.

5. OECD. Health at a Glance: Europe 2016 State of Health in the EU Cycle. 2016 https://ec.europa.eu/health/sites/health/files/state/docs/ health_glance_2016_rep_en.pdf (Accessed 10 April 2017).

6. Allebeck P, Mastekaasa A. Chapter 5. Risk factors for sick leave general studies. Scand J Public Health 2004;32(63 suppl):49-108.

7. Wang M, Mittendorfer-Rutz E, Dorner TE, et al. Determinants of work disability following lumbar spine decompression surgery. Scand $J$ Public Health 2019;47.

8. Goorts K, Rusu D, Vandenbroeck S, et al. 790 Predicting longterm sickness absence and supporting return-to work processes using questionnaires. Occupational and Environmental Medicine 2018;75:A555-A556.

9. Ubalde-Lopez M, Delclos GL, Benavides FG, et al. Measuring multimorbidity in a working population: the effect on incident sickness absence. Int Arch Occup Environ Health 2016;89:667-78.

10. Dekkers-Sánchez PM, Hoving JL, Sluiter JK, et al. Factors associated with long-term sick leave in sick-listed employees: a systematic review. Occup Environ Med 2008;65:153-7.

11. Arcas MM, Delclos GL, Torá-Rocamora I, et al. Gender differences in the duration of non-work-related sickness absence episodes due to musculoskeletal disorders. J Epidemiol Community Health 2016;70:1065-73.

12. Gabbay M, Shiels $C$, Hillage J. Factors associated with the length of fit note-certified sickness episodes in the UK. Occup Environ Med 2015;72:467-75

13. Alba-Ramirez A, López-Mourelo E. Sickness absence from work in Spain: are there gender differences? Universidad Carlos III de Madrid Working papers 2017:17-15 http://hdl.handle.net/10016/25937 (Accessed 12 March 2019).

14. Akerstedt T, Kecklund G, Selén J. Disturbed sleep and fatigue as predictors of return from long-term sickness absence. Ind Health 2010;48:209-14.

15. Johnsson A, Fornander T, Rutqvist LE, et al. Predictors of return to work ten months after primary breast cancer surgery. Acta Oncol 2009;48:93-8.

16. Amick BC, McLeod CB, Bültmann U. Labor markets and health: an integrated life course perspective. Scand J Work Environ Health 2016;42:346-53.

17. Virtanen P, Siukola A, Lipiäinen L, et al. Trajectory analyses of sickness absence among industrial and municipal employees. Occup Med 2017;67:109-13.

18. Haukka E, Kaila-Kangas L, Ojajärvi A, et al. Pain in multiple sites and sickness absence trajectories: a prospective study among Finns. Pain 2013;154:306-12

19. Feleus A, Miedema HS, Bierma-Zeinstra SM, et al. Sick leave in workers with arm, neck and/or shoulder complaints; defining occurrence and discriminative trajectories over a 2-year time period. Occup Environ Med 2017;74:114-22.

20. Haukka E, Kaila-Kangas L, Luukkonen R, et al. Predictors of sickness absence related to musculoskeletal pain: a two-year follow-up study of workers in municipal kitchens. Scand J Work Environ Health 2014;40:278-86. 
21. Wang M, Vaez M, Dorner TE, et al. Trajectories and characteristics of work disability before and after acute myocardial infarction. Heart 2018;104:340-8.

22. Farrants K, Friberg E, Sjölund S, et al. Work disability trajectories among individuals with a sick-leave spell due to depressive episode $\geq 21$ days: A prospective cohort study with 13-month follow up. J Occup Rehabil 2018;28:678-90.

23. López Gómez MA, Durán X, Zaballa E, et al. Cohort profile: the Spanish WORKing life Social Security (WORKss) cohort study. BMJ Open 2016;6:e008555.

24. Nylund KL, Asparouhov T, Muthén BO. Deciding on the number of classes in latent class analysis and growth mixture modeling: A monte carlo simulation study. Structural Equation Modeling: $A$ Multidisciplinary Journal 2007;14:535-69.

25. van de Schoot R, Sijbrandij M, Winter SD, et al. The GRoLTS Checklist: Guidelines for Reporting on Latent Trajectory Studies. Struct Equ Model 2017;24:451-67.

26. World Health Organization. International Statistical Classification of Diseases and Related Health Problems 10th Revision. 2010;2 https://www.who.int/classifications/icd/ICD10Volume2_en_2010.pdf Accessed 12 Dec 2018

27. Laaksonen M, Blomgren J, Gould R. Sickness allowance trajectories preceding disability retirement: a register-based retrospective study. Eur J Public Health 2016;26:1050-5.

28. Delclós J, Gimeno D, Torá I, et al. [Distribution of the duration of nonoccupational sick leave by medical diagnosis (Catalonia, Spain, 2006-2008)]. Gac Sanit 2013;27:81-3.

29. Savikko A, Alexanderson K, Hensing G. Do mental health problems increase sickness absence due to other diseases? Soc Psychiatry Psychiatr Epidemiol 2001;36:310-6.

30. Wise J. Audit finds large variations in NHS staff sick days. BMJ 2011;342:d953.

31. McGee R, Bevan S, Quadrello T. Fit For Work? Musculoskeletal Disorders and the Dutch Labour Market. The Work Foundation 2009.

32. Benjamin S, Morris S, McBeth J, Beth JMC, et al. The association between chronic widespread pain and mental disorder: A populationbased study. Arthritis \& Rheumatism 2000;43:561-7.

33. Currie SR, Wang J. Chronic back pain and major depression in the general Canadian population. Pain 2004;107:54-60.
34. Ubalde-López M, Delclos GL, Calvo E, et al. Influence of new secondary diagnoses on the duration of non-work-related sickness absence episodes. J Occup Environ Med 2013;55:460-4.

35. Ministerio de Empleo y Seguridad Social. Procedimiento de gestión de la prestación de Incapacidad Temporal. 2017 http://www.segsocial.es/wps/portal/wss/internet/InformacionUtil/44539/44667? changeLanguage =en (Accessed 7 Mar 2017).

36. Real Decreto Legislativo $8 / 2015$, de 30 de octubre, por el que se aprueba el texto refundido de la Ley General de la Seguridad Social. Boletín Of. del Estado 2015:103291-103519 http://www.boe.es/boe/ dias/2015/10/31/pdfs/BOE-A-2015-11724.pdf (Accessed 28 Feb 2017).

37. Benach J, Vives A, Tarafa G, et al. What should we know about precarious employment and health in 2025? Framing the agenda for the next decade of research. Int J Epidemiol 2016;45:232-8.

38. Salas-Nicás S, Moncada S, Llorens C, et al. Cognitive and Affective Insecurity Related to Remaining Employed and Working Conditions: Their Associations With Mental and General Health. J Occup Environ Med 2018;60:e589-94.

39. Susser P, Ziebarth NR. Profiling the U.S. Sick Leave Landscape: Presenteeism among Females. Health Serv Res 2016;51:2305-17.

40. Böckerman P, Kanninen O, Suoniemi I. A kink that makes you sick: The effect of sick pay on absence. J Appl Econ 2018;33:568-79.

41. Ziebarth NR, Karlsson M. The effects of expanding the generosity of the statutory sickness insurance system. J Appl Econ 2014;29:208-30.

42. Virtanen M, Kivimäki M, Joensuu M, et al. Temporary employment and health: a review. Int J Epidemiol 2005;34:610-22.

43. Waenerlund AK, Virtanen P, Hammarström A. Is temporary employment related to health status? Analysis of the Northern Swedish Cohort. Scand J Public Health 2011;39:533-9.

44. Waenerlund AK, Gustafsson PE, Virtanen P, et al. Is the coreperiphery labour market structure related to perceived health? findings of the Northern Swedish Cohort. BMC Public Health 2011;11:956.

45. Hensing G. Chapter 4. Methodological aspects in sickness-absence research. Scand J Public Health 2004;32:44-8. 